Annals of Plant Sciences

ISSN: 2287-688X

OPEN ACCESS

Research Article

www.annalsofplantsciences.com

\title{
In-silico identification of cis- acting regulatory elements in 5', regulatory region of Betaine aldehyde dehydrogenase isoenzymes of selected monocot and dicot
}

Hemani Sharma*, Sumit Govil and Divya Shrivastava

School of Life sciences, Jaipur National University, Jagatpura, Jaipur, India

Received: 1/9/2018; Accepted: 1/20/2018

\begin{abstract}
It's challenging to understand the multifarious gene regulatory networks. Diverse biological processes, are mostly conferred by nature of cis-acting regulatory elements (CARE) located within the regulatory region which include abiotic stress responses, hormone responses and developmental processes. Thus, the identification of CARE and their organization is a crucial step for better understanding of spatiotemporal expression of the gene. The putative cis-acting element that are located within the 5' regulatory region of BADH isozymes of Hordeum vulgare, Oryza sativa, Sorgbum bicolor, Leymus chinensis, Zoysia tenuifolia, Arabidopsis thaliana, Amarantbus bypochondriacus, Chrysanthemum lavandulifolium, Populus euphratica and Atriplex prostrate were identified using bioinformatics tools. Several probable cis-acting regulatory elements that are coupled with cellular development, hormonal and stress response were identified as: Me-JA, GARE, GT-1, MYB, W-box, I-box, Pyrimidine-box, ANAERO, ARF, CARE, ASF1, SORLIP, SURE, TAAAGSTKST1, GCC Box, CICADIAN, Sp1 and CGCG Box. These results shed light on probable cis-acting regulatory elements these $\mathrm{BADH}$ isoenzyme that confer their expression and regulation during cellular, hormonal and stress response.
\end{abstract}

Keywords: Biotic and abiotic stress, Betaine aldehyde dehydrogenase (BADH), Cis-acting regulatory elements, Cellular development, Hormonal regulation, Spatiotemporal

\section{Introduction}

Gene expression is a completely controlled process that exists at various levels and transcription is one of the most essential step (Wyethand Albin, 2004). In plants more than 1500 transcription factors are involved to control the expression of target gene in complex signaling network and transcription rate of gene located in the promoter region (Doelling and Pikaard, 1995). In plants the regulatory/promoter region of gene is located primarily in the untranslated region of DNA sequence (about 1000 1500 base pairs upstream) accountable for its activity, modulation of the neighboring regions of translated DNA and coordinate expressions (Chaboute et al., 2002).

The promoter region consists of peculiar DNA sequences and responsive elements that act in the calling of regulatory proteins that aid in transcription of the protein-coding region of the gene. Each gene contains a specific combination of cis-acting regulatory sequence elements in their 5'regulatory region. Cis-acting regulatory elements are vital transcriptional gene regulatory units; that establish distinct spatiotemporal transcriptional activity (Qui, 2003). Hence identification and understanding of the cis-acting regulatory region bound by TFs that control gene expression will put forward the crucial information to elaborate the mechanism that how and what external stimulus may be involved in their expression. Thus, a full

\footnotetext{
*Corresponding Author:

Hemani Sharma,

PhD student, School of Life Sciences,

Jaipur National University,

Jagatpura, Jaipur, India.

E-mail: himani6606@gmail.com
}

understanding of the transcriptional gene regulation system will depend on successful functional analyses of cis-acting elements.

As well acknowledged, various environs stresses, such as the drouth, saltiness and high/low temperature have hostile result on plant expansion, development and productivity (Shinozaki and Yamaguchi, 2003). By the nature, plants have developed highly intricate mechanisms and numerous response to different environs stresses that may entail the renovation of cellular homeostasis, stress induced protein expression, synthesis of anti-microbial products; for resistant, and addition of compatible solutes such as glycine betaine (Cherian and Reddy, 2003). Glycine betaine key role in cellular osmotic adjustment, elevating drought resistance, plasma membrane integrity, also acts as a molecular chaperone by helping to stabilize protein structure and function in plants under environs stress (Bartels and Sunkar, 2005; Allakhverdiev et al., 2008). In, Plants synthesis of glycine betaine involves two enzyme; first step oxidation catalyzed by choline monooxygenase (CMO) and second by betaine aldehyde dehydrogenase (BADH) (Rhodes and Hanson, 1993). BADH is an enzyme implicated in the biosynthesis of glycine betaine, the amount of glycine betaine exhibit in a specific plant tissue which is greatly associated and mostly controlled by 
statuses of environmental that can permit particular transcriptional-translational expressions of BADH genes. Various paralogous genes, which encode several isozymes of BADH were acknowledge and characteristically present in few plants. The studies also revealed and proposed that incidence of evolutionary divergence between monocot and dicot BADH isoenzymes (Munoz-Clares et al., 2014) was due to several gene duplication which result in creation of many isozymes (Julian-Sanchez et al., 2007). However, till now, only narrow information is present regarding BADH genes. Transcriptional phenomenon is generally regulated by binding of transcriptional elements to their related cis-acting elements positioned at affected gene promoter (Lee et al., 2002). In plants, various stresses coupled cisacting regulatory elements that trigger transcript in reposte to abiotic factors, wound and pathogen response had been predicted (Ibraheem et al., 2010). At present, work done on the cis-acting regulatory elements that modulate expression of $\mathrm{BADH}$ isozymes reported in abiotic and/or biotic stress is very scarce. Thus, the identification of CARE and their organization is a key step to fructify understanding expression/regulation of genes. Hence, our objective was to use accessible bioinformatics tools to reveal broad explanation and rate of occurrence of vital cis-regulatory elements positioned in the 5' untranslated (5'UTR) DNA (promoter region, Folorunsho et al., 2014) of $\mathrm{BADH}$ isozymes of selected monocot and dicot plant. This analysis reveals transcription regulatory interactions of these isozymes during development or under environmental stress conditions. Hence, in-silico identification of cis-acting regulatory elements will render additional perceptivity of gene expression and regulation. In addition, this information may assist in development of higher yields tolerant varieties in plant breeding programmes.

\section{Materials and Methods}

Data source:

The complete nucleotide sequence, 5'UTR and the $\mathrm{CDS}$ of $\mathrm{BADH}$ isoenzymes of (Hordeum vulgare, Oryza sativa, Sorghum bicolor, Leymus chinensis, Zoysia tenuifolia: Monocot) (Arabidopsis thaliana, Amaranthus bypochondriacus, Chrysanthemum lavandulifolium, Populus euphratica, Atriplex prostrate: Dicot) registered in GenBank was obtained from National center for Biotechnology information

(NCBI) (http://www.ncbi.nih.nim.gov)

data).

(Supplymentary

Identification and analysis of Cis-acting regulatory elements:

Detection of the CARE by scanning 5'UTR of $\mathrm{BADH}$ isozymes for the occurrence of probable CRE exactly alike or related motifs recorded in Genomatix

Matinspector (http://www.genomatix.de/cgi-

bin/matinspectorprof/matfam.p1; Cartharius et al., 2005), PlantPan (http://PlantPan.mbc.nctu.edu.tw; Chang et al., 2008) and PlantCARE(http://bioinformatics.psb.ugent.be/we btools/plantcare/cgibin/CallMatIE5.htpl; Lescot et al., 2002).

\section{Prediction of Simillarities/Divergence:}

Identity/Dissimilarity among the 5' UTR, coding and protein sequences of $\mathrm{BADH}$ isozymes of selected monocots and dicots were also identified using Clustal Omega: EMBL-EBI, (http://www.ebi.ac.uk/Tools/clustalo/; $\quad$ Mc Williams et al., 2013)

\section{Results and Discussion}

There are numerous bioinformatics tools on the World Wide Web that makes analysis on the gene expression modulation of interest more accessible. Gene transcript initiation and inactivation in the biological pathway include binding of cis-element to transcription factors in the affected gene promoter (Lindolf et al., 2009). In the selected monocot and dicot plant species, spatial location of the putative cis-acting regulatory elements indicates that; HvBBD1, OsBADH1, AtBADH1 at the distal region expression of genes might be well regulated, while HvBBD2, SbBADH2, AtBADH2, ZtBADH1, AhBADH1, ClBADH1, ClBADH2 have the cis-acting regulatory elements evenly spread across 5' region. However LsBADH2, PeBADH1, PeBADH2 expression of genes is at proximal region. The alignment results of protein, coding and non-coding sequence of monocot and dicot is as presented in Table 1, Table 2 and Table3. The analysis of protein sequence in selected monocot and dicot also revealed high conservation in these sequences (Table 1). The coding region of BADH isoenzyme of monocot and dicot plant species seems to be more conserved (Table 2) where as high divergence appeared in 5' regulatory region of selected monocot and dicot (Table 3).

Table 1: Range of coding sequence homology expressed in $\%$ between selected monocot and dicot $\mathrm{BADH}$ isoenzyme

\begin{tabular}{clllll}
\hline Isozyme (A) & Isozyme (B) & Range of homology (\%) & Isozyme (A) & Isozyme (B) & Range of homology (\%) \\
\hline \multirow{6}{*}{ Barley } & Barley & $66 \%$ & & Rice & $62.80 \%$ \\
& Rice & $60.40-78.10 \%$ & & Sorghum & $54.70-78.10 \%$ \\
& Sorghum & $53.10-73.50 \%$ & Arabidopsis & $62.60-64.70 \%$ \\
& Leymus & $61.50-85.30 \%$ & Rice & Zoysia & $62.50-79.40 \%$ \\
& Zoysia & $65.30-77.50 \%$ & & Amaranthus & $14.60-70.70 \%$ \\
& Amaranthus & $17.00-56.70 \%$ & Chyrsanthmum & $58.60-61.80 \%$ \\
& Chyrsanthmum & $61.80-63.50 \%$ & Atriplex & $50.30-64.10 \%$ \\
\hline
\end{tabular}




\begin{tabular}{|c|c|c|c|c|c|}
\hline & Atriplex & $48.50-65.30 \%$ & & Populus & $60.50-71.10 \%$ \\
\hline & Populus & $58.10-58.60 \%$ & & Arabidopsis & $71.0 \%$ \\
\hline & Arabidopsis & $55.10-64.90 \%$ & \multirow{4}{*}{ Arabidopsis } & Leymus & $52.90-67.50 \%$ \\
\hline & Leymus & $47.10-66.40 \%$ & & Amaranthus & $16.60-69.70 \%$ \\
\hline & Zoysia & $56.10-79.80 \%$ & & Chyrsanthmum & $67.30-70.30 \%$ \\
\hline & Amaranthus & $13.90-59.40 \%$ & & Atriplex & $57.20-69.40 \%$ \\
\hline & Chyrsanthmum & $54.30-64.40 \%$ & \multirow{5}{*}{ Leymus } & Populus & $70.50-72.50 \%$ \\
\hline & Atriplex & $53.00-64.40 \%$ & & Leymus & $56.50 \%$ \\
\hline & Populus & $54.70-60.00 \%$ & & Zoysia & $59.90-77.40 \%$ \\
\hline \multirow{4}{*}{ Amaranthus } & Amaranthus & $18.80 \%$ & & Atriplex & $51.10-65.00 \%$ \\
\hline & Chyrsanthmum & $17.10-66.10 \%$ & & Populus & $59.90-62.00 \%$ \\
\hline & Atriplex & $14.90-74.20 \%$ & \multirow{3}{*}{ Chyrsanthmum } & Chyrsanthmum & $92.90 \%$ \\
\hline & Populus & $15.70-75.30 \%$ & & Atriplex & $54.60-70.20 \%$ \\
\hline \multirow{2}{*}{ Atriplex } & Atriplex & $61.90 \%$ & & Populus & $64.50-69.10 \%$ \\
\hline & Populus & $63.40-66.20 \%$ & Populus & Populus & $92.60 \%$ \\
\hline
\end{tabular}

Table 2. Range of non-coding sequence homology expressed in $\%$ between selected monocot and dicot BADH isoenzyme

\begin{tabular}{|c|c|c|c|c|c|}
\hline Isozyme (A) & Isozyme (B) & Range of homology (\%) & Isozyme (A) & Isozyme (B) & Range of homology (\%) \\
\hline \multirow{11}{*}{ Barley } & Barley & $41.90 \%$ & \multirow{9}{*}{ Rice } & Sorghum & $1.50 \%$ \\
\hline & Rice & $27.40-32.60 \%$ & & Arabidopsis & $7.70-38.00 \%$ \\
\hline & Sorghum & $33.60-34.40 \%$ & & Leymus & $20.40-29.30 \%$ \\
\hline & Arabidopsis & $17.00-36.50 \%$ & & Zoysia & $10.90-26.0 \%$ \\
\hline & Leymus & $30.40-66.70 \%$ & & Amaranthus & $4.20 \%$ \\
\hline & Zoysia & $12.30-36.00 \%$ & & Chyrsanthmum & $16.60-21.0 \%$ \\
\hline & Amaranthus & $2.20-3.60 \%$ & & Atriplex & $2.70 \%$ \\
\hline & Chyrsanthmum & $2.40-37.50 \%$ & & Populus & $9.20-35.00 \%$ \\
\hline & Atriplex & $4.30-4.40 \%$ & & Arabidopsis & $20.90-28.90 \%$ \\
\hline & Populus & $16.40-24.50 \%$ & \multirow{6}{*}{ Sorghum } & Leymus & $11.50-34.70 \%$ \\
\hline & Arabidopsis & $24.50 \%$ & & Zoysia & $17.70-41.30 \%$ \\
\hline \multirow{6}{*}{ Arabidopsis } & Leymus & $18.50-28.80 \%$ & & Amaranthus & $4.50 \%$ \\
\hline & Zoysia & $15.50-28.80 \%$ & & Chyrsanthmum & $28.30-31.10 \%$ \\
\hline & Amaranthus & $2.40-6.00 \%$ & & Atriplex & $2.20 \%$ \\
\hline & Chyrsanthmum & $19.80-40.20 \%$ & & Populus & $20.00-30.20 \%$ \\
\hline & Atriplex & $2.30-5.40 \%$ & \multirow{7}{*}{ Leymus } & Leymus & $22.0-3.70 \%$ \\
\hline & Populus & $12.0-32.10 \%$ & & Zoysia & $18.50-34.70 \%$ \\
\hline \multirow{5}{*}{ Zoysia } & Zoysia & $14.50 \%$ & & Amaranthus & $1.4-1.9 \%$ \\
\hline & Amaranthus & $1.3-4.90 \%$ & & Chyrsanthmum & $14.70-27.70 \%$ \\
\hline & Chyrsanthmum & $13.10-31.40 \%$ & & Atriplex & $4.40-9.70 \%$ \\
\hline & Atriplex & $2.50-8.30 \%$ & & Populus & $16.20-31.60 \%$ \\
\hline & Populus & $4.4-29.40 \%$ & & Chyrsanthmum & $5.60-6.40 \%$ \\
\hline \multirow{3}{*}{ Chyrsanthmum } & Chyrsanthmum & $81.9 \%$ & \multirow[t]{2}{*}{ Amaranthus } & Atriplex & $0.20 \%$ \\
\hline & Atriplex & $1.8-2.4 \%$ & & Populus & $1.20-4.30 \%$ \\
\hline & Populus & $14.30-44.60 \%$ & Atriplex & Populus & $3.20-14.30 \%$ \\
\hline Populus & Populus & $14.90 \%$ & & & \\
\hline
\end{tabular}

Table 3. Protein identity matrix in $\%$ between selected monocot and dicot BADH isoenzyme

\begin{tabular}{ccc}
\hline Isozyme (A) & Isozyme (B) & Identity \\
\hline HvBBD1 & HvBBD2 & $71.33 \%$ \\
OsBADH1 & OsBADH2 & $77.2 \%$ \\
SbBADH1 & SbBADH2 & 66.57 \\
AtBADH1 & AtBADH2 & 79.44 \\
LsBADH1 & LsBADH2 & 71.95 \\
AhBADH1 & AhBADH2 & 97.73 \\
ZtBADH1 & ZtBADH2 & 74.55 \\
ClBADH1 & ClBADH2 & 98.65 \\
ApBADH1 & ApBADH2 & 83.52 \\
PuBADH1 & PuBADH2 & 92.55 \\
\hline
\end{tabular}

Hormonal regulatory motif

$\begin{aligned} \text { HvBBD1 } & \\ & =\text { } \\ & =\text { TGACACG } \\ & =\text { ASF1MOTIF } \\ & =\text { CGCG box } \\ & =\mathrm{PBOX}\end{aligned}$
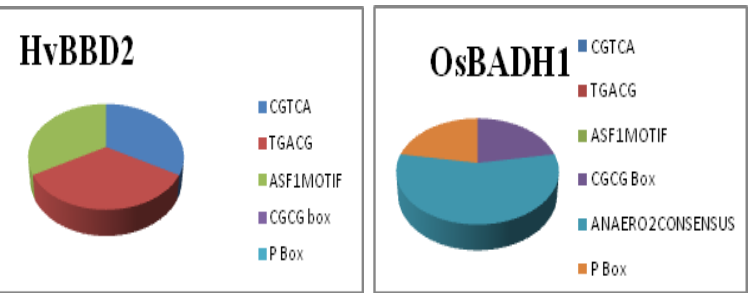


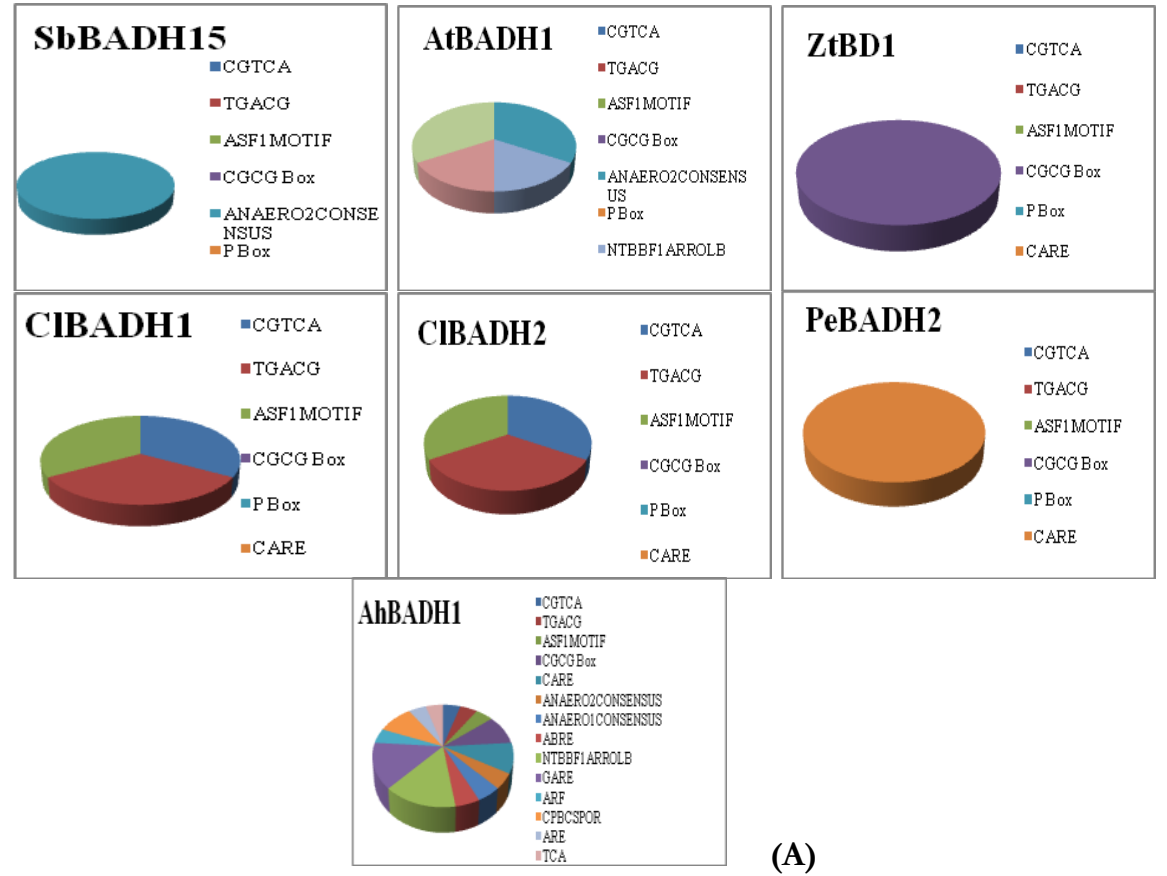

Fig. 1. Illustration of the frequencies of the cis-acting regulatory elements (hormonal regulatory motif) identified within the regulatory regions of $\mathrm{BADH}$ isoenzyme of selected monocot and dicot

Stress regulatory motif

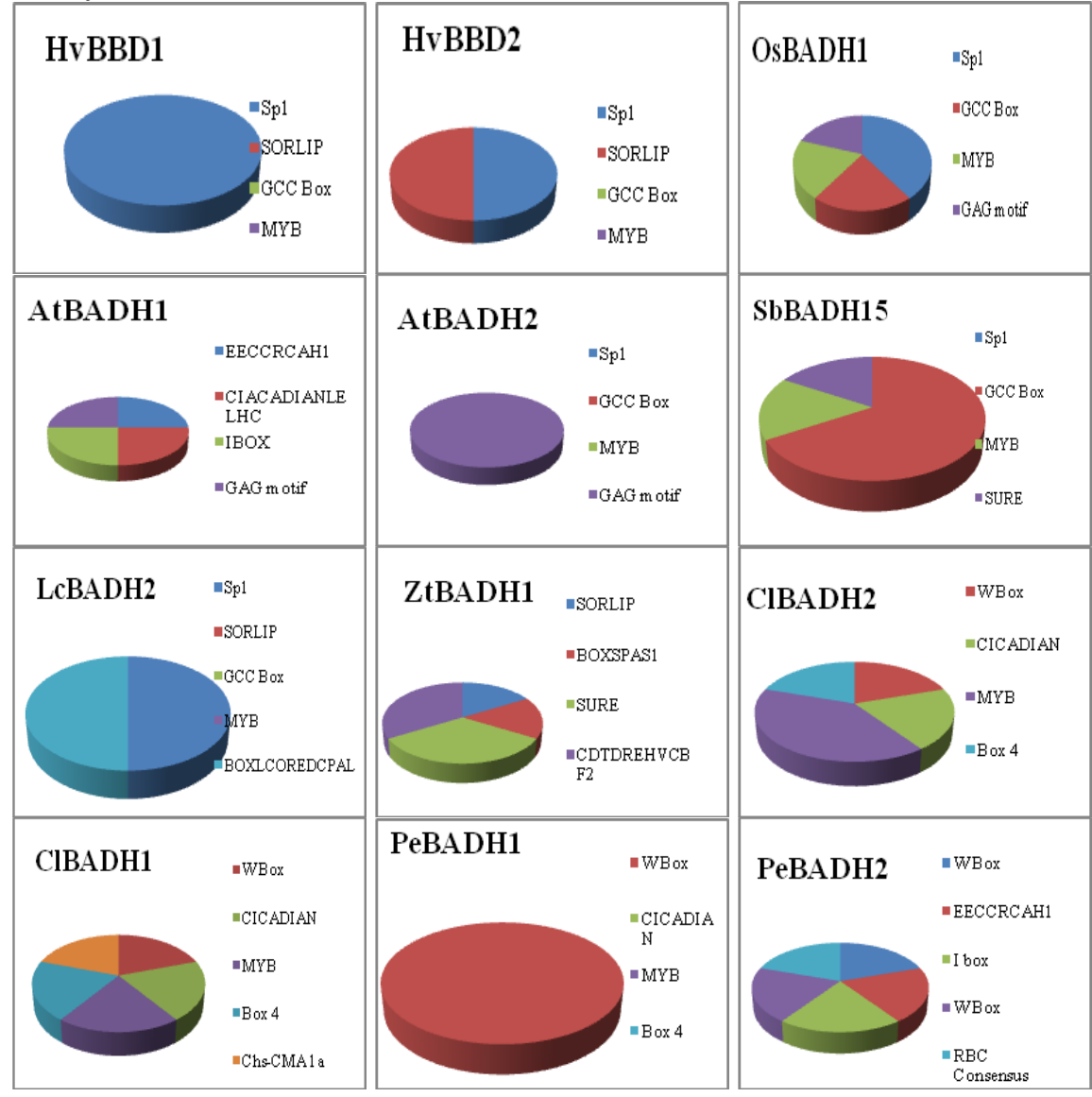




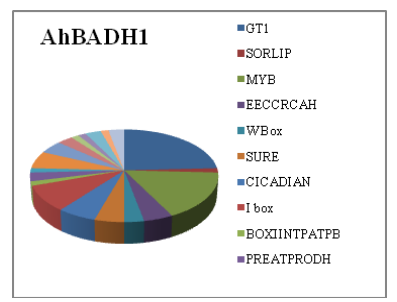

Fig. 2. Illustration of the frequencies of the cis-acting regulatory elements (stress regulatory motif) identified within the regulatory regions of $\mathrm{BADH}$ isoenzyme of selected monocot and dicot

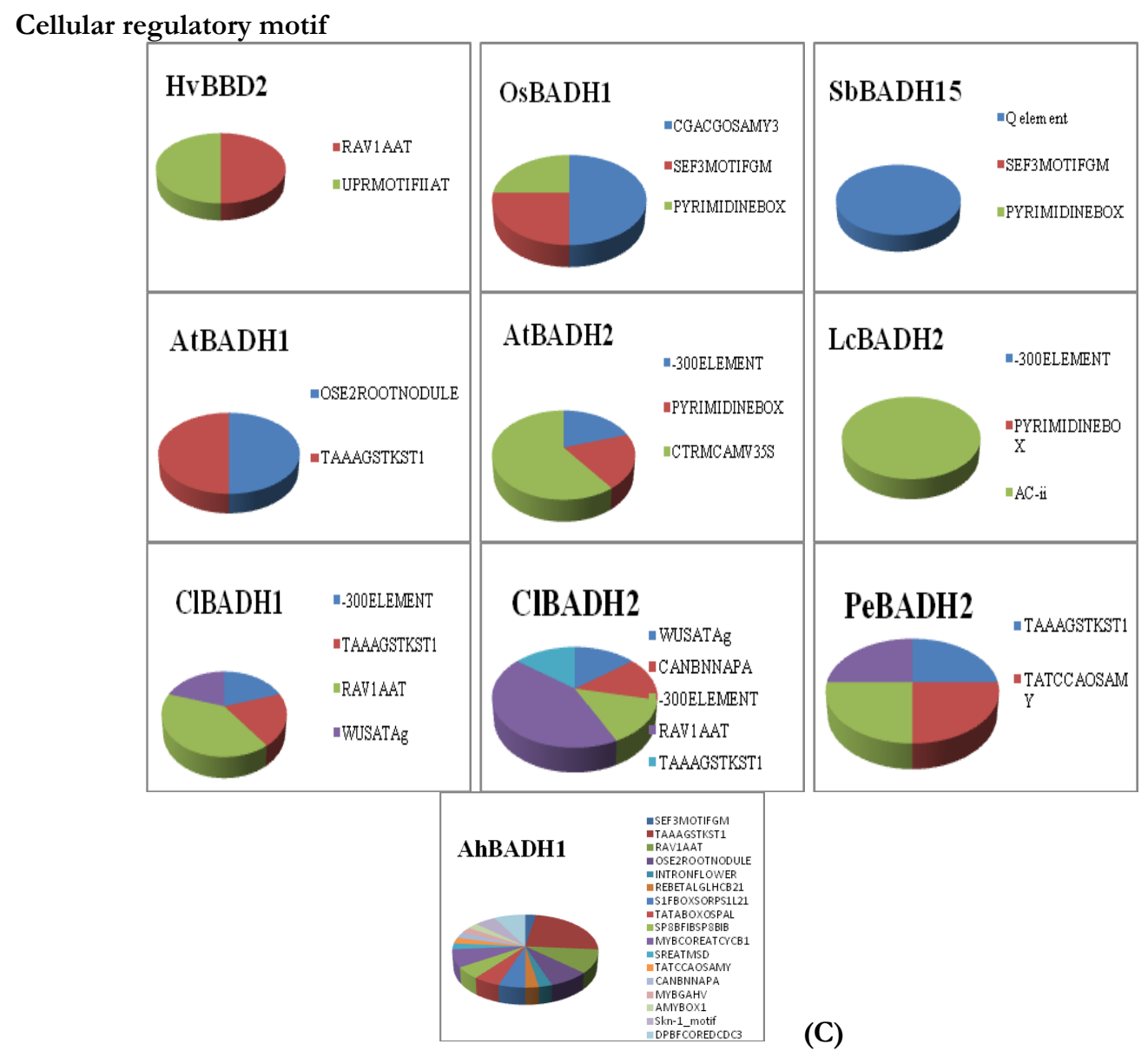

Fig. 3. Illustration of the frequencies of the cis-acting regulatory elements (cellular regulatory motif) identified within the regulatory regions of $\mathrm{BADH}$ isoenzyme of selected monocot and dicot

Sp1, GAG, Box-4, Box-I, G box, I box, L box, LAMP element, Circadian, chs-Unit $1 \mathrm{~m} 1$ and chsCMA1a motif were found with variable frequency in the regulatory regions that are associated with the light response (Lam and Chau, 1989). Light is an important factor which checks the circadian rhythm of diverse processes, for example growth, development, nitrate uptake, flowering, seed development and stress responses in plants (Kumar et al., 2009; Natr and Lawlor, 2005). Sp1 motif was found only in regulatory regions of HvBBD1, HvBBD2, OsBADH1 and LcBADH2 whereas GAG motifs were found only in OsBADH1and AtBADH1. Of worth noting Box-4, G-Box, L Box, LAMP, chs-Unit $1 \mathrm{~m} 1$ and chs-CMA1a motif was only found in AhBADH1. I box motif found only in AtBADH2, AhBADH1, PeBADH2; a conserved sequence in both monocots and dicots promoters of genes regulated by light (Terzaghi and Cashmore, 1995). In addition, CIACADIANLELHC essential for expression of circadian identified in the promoter region of (Lhc) genes in tomato (Piechulla et al.,1998) was only found in AtBADH2 and AhBADH1 and SORLIP a key component in the light-inducible activity were found in $\operatorname{HvBBD} 1$, ZtBADH1, AhBADH1. It thus reflects BADH isoenzyme of selected monocot and dicot significantly influenced by light or through the involvement of particular specific receptor riposte to light. Although various binding factors and several light-responsive cis-elements (LREs) were discovered, none solo element has been acknowledged to only confabulate light sensitivity to minimal heterologous promoters (Lopez-Ochoa 
et al., 2007). Hence, it will be combinations of different CARE relevant for (LREs), instead of individual elements, are needed to confabulate light responsiveness alone (Chattopadhyay et al., 1998). The $\mathrm{W}$ boxes are main CARE accountable for the pathogen was detected in the case of all BADH isoenzymes of Amaranthus, Chrysanthemum and Populus. Their presence merely indicates that $\mathrm{BADH}$ are wound responsive proteins and will be greatly modulated by wounding. This still ought to be elucidated in so as to establish response regulation of $\mathrm{BADH}$ isoenzyme. In previously studies, BOXLCOREDCPAL found in promoter region of DcMYB1 which activate transcription of the DcPAL2 gene in reponse to elicitor treatment (Maeda et al., 2005). This would imply a MYB directed signaling pathway is triggered synthesize metabolites that facilitate defense responses. Another cis-element PREATPRODH found in Amaranthus known for Pro- or hypoosmolarity activate transcription of proline dehydrogenase gene in riposte to L-Proline and hypoosmolarity (Satoh et al., 2004). It is important to refer the presence of the GCC-box which was present in OsBADH1 and SbBADH2, has been notifiable as numerous PR (Pathogensis-related) genes. Furthermore, GT1element (for pathogen attack, light and salicylic acid) solely present in AhBADH1. GT-1 element found in the regulatory region of SCaM-4 from soybean (Glycine max) plays an important role in expression of SCaM-4 gene in riposte to pathogen and salt (Park et al., 2004). EECCRCAH1 (for CO2) present in AtBADH1, AhBADH1, PeBADH2 and ClBADH2. Hbox consensus necessary for both light and elicitor stimulation restricts to AhBADH1. The presence of these elements may further be evidence of their rapid induction in stressed condition. The Heat Stress Element (HSE) was identified in regulatory region of AhBADH1. This cis-acting element helps to maintain a cell turgor for plant survival during high temperature stress (Larkindale and Vierling, 2008). The DRE element was only identified in regulatory region of ZtBADH1. This cis-acting element has been reported in modulating expression profiles of gene in abiotic stress conditions in plant (Dubouzet et al., 2003). The occurrence of these motifs may connote the ability of gene to survive/acclimatize or the participation or need for glycine betaine during high/low temperature stress condtions. Li et al., (2015); Tian et al., (2017) also reported the function of glycine betaine in maintaining photosynthetic activity under stress conditions. Sulphur is a fundamental nutrient that is necessary for ontogenesis and plant yield (Hopkins, 1999) found in SbBADH2, ZtBADH1, and AhBADH1. P-box, CARE and GARE-motif detected in the regulatory regions of Rice, Arabidopsis, Populus and Amaranthus respectively that are associated to the gibberellin responsive element. In some promoters a single GARE motif is proficient to direct transcription at a high level which is hormonally regulated as it collaborate with different CARE (Rogers et al.,1994). CPBCSPOR a cis-acting element specific for cytokinin induction restricts to AhBADH1 (Fusada et al., 2005). TC-rich repeats implicate with stress/ defense related responses and are uniquely found in AhBADH1. TCA, implicated to salicylic acid sensitivity reported in non-coding regions of several genes of monocot as well as dicot plant which are stimulated by single or more than one form of stress (Goldsbrough et al., 1993). Salicylic acid (SA) induces the synthesis of pathogenesis associated protein and serves as a signaling molecule in plants detected in regulatory region of AhBADH1. SA facilitates plants to survive in stress conditions by stimulating biochemical and physiological mechanism (Khodary, 2004). Hence, occurrence of these motifs might indicate again the cooperative interaction between $\mathrm{BADH}$ isoenzyme and stress response proteins. Similarly, ASF1MOTIFCAMV found in Barley, Zoysia, and Chrysanthemum involved in stimulation of transcription of numerous genes by auxin and/or salicylic acid. With the exception of Rice, Arabidopsis, Leymus, Zoysia and Populus all other BADH isoenzymes in Barley, Amaranthus and Chrysanthemum may be regulated by MEJA and it has been reported in many wound/pathogensensitive genes in monocot as well as dicotyledonous plants in 5' regions (Rushton and Somssich, 1998). JA is reported to be involved in the drought-evoked betaine accretion in pear leaves (Gao et al., 2004). The occurrence of the MeJA in the 5' regions of some of $\mathrm{BADH}$ isoenzyme infers a possible function in wound and stress signaling. LECPLEACS2 a cis-element of an elicitor-induced expression found in Arabidopsis; reported in solanum lycopersicum Acs2 gene for ethylene biosynthesis (Matarasso et al., 2005). A process might be linked to synthesis of glycine betaine grounded on in-silico analysis is their involvement in reposite to flooding for the reason of occurrence of ANAERO1-3 consensus found to be spread within the regulatory region of Rice, Arabidopsis and Amaranthus. These consensus were reported in the promoter of anaerobically induced genes implicated in fermentation reaction (Mohanty et al., 2005). Therefore, we may speculate that flood-response provide protective covering to cell against the acidification of cytosol (Zang et al., 2000) plant growth may be modulated by $\mathrm{BADH}$ isoenzyme. ABRE cis-acting element has been well-known to aid drought tolerance in seeds, physiological changes such as: seed (growth and ontogeny)( Finkelstein and Gibson, 2002). ARF: Auxin response factor functionally identified in primary/early response genes where they adhere to auxin responsive element. Meanwhile, another CARE NTBBF1ARROLB implicated in tissuespecific expression and auxin keyed out in Arabidopsis and Amaranthus (Baumann et al., 1999). Although ARF, ABRE found only in Amaranthus at low frequencies, so it effects on 
genes may perhaps increase or suppress the transcription of genes relative to the kind of plant tissue wherein they're expressed. The cis-element CGCGBOX reported in promoters region of genes involved in ethylene, abscisic acid and light perception (Yang and Poovaiah, 2002) was found only in Rice, Zoysia and Amaranthus. In addition, a very interesting element WUSATAg has been solely identified at very low frequency in CIBADH1and $\mathrm{ClBADH} 2$ reported as a target sequence of WUS in AGAMOUS gene in Arabidopsis (Lohmann et al., 2003).Motifs coupled with sugar responsiveness as well as repression in expression of gene such as pyrimidine-box was located in OsBADH1 and AtBADH2. Similarly another cis-acting element implicated in sugar signaling response SREATMSD (Tatematsu et al., 2005) detected in regulatory region of PeBADH2 and AhBADH1. On the contrary, the sugar responsiveness (Hwang et al., 1998) CGACGOSAMY3 box is carried only by ZtBADH1, OsBADH1 and not by the other $\mathrm{BADH}$ isoenzymes. Another sugar related sequence TATCCAOSAMY found in promoter of alpha amylase mediate sugar and seed expression during germination (Chen et al., 2006) located in regulatory region of AhBADH1 and PeBADH2. MYBGAHV is a cis-acting regulatory element partially implicated in sugar repression and reported in alpha amylase gene for GA response (Gubler et al., 1995) was lower in AhBADH1 and absent in other BADH isoenzymes. This would entail that the expression profile of those genes could be modulated by levels of sugar, yet their sensitivity and physiological significance of identified cis-elements in 5' region will require to be identified by reporter gene experiments. Similarly, another explicit cis-element strongly restricts to Zoysia and Amaranthus the motif MYBCOREATCYCB1 require for activation of transcription of cyclin B1at two different phase of cell cycle (Trehin et al., 1997). Different TATA boxes such as TATAAAT, TATATAA and TATTAAT were manifest only in regulatory region of AtBADH2, AhBADH1, ClBADH1 and CIBADH2. TATA boxes are implicated in the expression of beta phaseolin gene of Phaseolus vulgaris (bean), responsible for encoding a seed storage protein in bean (Grace et al., 2004). Another cis-regulatory element, CAATBOX1 reported in promoter for particular tissue activity of a pea legumin gene in tobacco (Shirsat et al., 1989) has been found in AtBADH2, AhBADH1, ClBADH1, $\mathrm{ClBADH} 2$ and PeBADH2. It is important to mention 5' UTR Py-rich stretch which is known to confer elevate transcription doesn't require any other upstream CARE except for a TATA-box was detected in AtBADH2 (Daraselia et al., 1996). There were some particular tissue elements such as, TAAAGSTKST1 for guard cell expression (Plesch et al., 2001) found in AtBADH1, AhBADH1, ClBADH1, $\mathrm{ClBADH} 2$ and PeBADH2; CANBNNAPA for embryo- and endospermspecific expression (Ellerstrom et al., 1996) located in ClBADH2 and AhBADH1; Skn-1 motif for endosperm expression (Washida et al., 1999) restricts to AhBADH1; Q Element for regulating pollen expression (Hamilton et al.,1998) restricts to SbBADH2; -300 element for seed storage protein (Forde et al., 1985) found in AtBADH2, ClBADH1 and ClBADH2; CTRMCAMV35S serve as an inverted GAGA element which enchance gene expression (Pauli et al., 2004) identified in AtBADH2; OSE2ROOTNODULE for nodule expression (Fehlberg et al., 2005) found in AtBADH1 and AhBADH1; RAV1AAT and RAV1BAT key regulator of various developmental process in plant and relatively high rosette leaf and root expression (Kagaya et al., 1999) detected in HvBBD2, AhBADH1, ClBADH1 and ClBADH2; REBETALGLHCB21 required for phytochrome regulation (Degenhardt and Tobin, 1996) found in AhBADH1; SEF3MOTIFGM for seed or embryo expression (Allen et al., 1989) found in OsBADH1, AhBADH1 and PeBADH2. Another, embryo specific element DPBFCOREDCDC3 reported in promoter of Dc3 gene of carrot (Kim et al., 1997) found in AhBADH1. CACT motif is a key element of Mem1 (mesophyll expression module1) (Gowik et al., 2004) found in regulatory region of Zoysia. Motif of AC II is essential for vascular specific expression (Lui et al., 2003) only found in Leymus. Furthermore, an AMY Box1 reported in alpha amylase promoter of rice, wheat and barley is responsible for regulating expression specific in seeds sprouting and callus (Huang et al., 1990) found in AhBADH1. In addition, MYB cis-elements were keyed out in regulatory region of $\mathrm{LcBADH} 2$, OsBADH1, SbBADH2 and AhBADH1. These ciselements had been accounted for drought inducibe gene expression. Thus, it is tempting to cogitate that the fuction of betaine aldehyde dehydrogenase is restricted tissue specific because of the occurrence of particular tissue cis-acting elements and may be modulated by various environmental stresses and hormone signals. Numerous putative cis-elements identified in non-coding regulatory region that may be involved in the regulatory process while some elements implicate in cell/tissue specific expression (Supplementary data). It is assumed that expression of gene is modulated by amalgamation of various regulatory factors conferring different effects in different cell/tissue (Qui, 2003). Hence genes that have related expression may have common cis-acting element in 5' regulatory regions (Vilo et al., 2000) which are key signature for a class of co-regulated genes. However, common CARE is one of the primary features of co-regulated genes and is frequently in regulatory region where they interact with complex protein (Wang et al., 2004).

\section{Conclusion}

Significant variations in nature and frequency observed in isoenzyme of selected monocot and dicot. Similar studies corroborate that isoenzyme 
usually loose common cis-acting element and as a result of evolution or gene duplication of parent gene the regulatory region may be well diverse (Folorunsho et al., 2014; Ibraheem et al., 2010; Lynch and Force, 2000). This computational analysis is based on bioinformatics approach and mainly focus on the relative study of putative ciselements keyed out in untranslated region of selected monocot and dicot. The analysis of these $\mathrm{BADH}$ isozymes gave an enhanced perceptive on how, when and type of external stimulus could be implicated in their expressions. However, transcription is littered with the conjuctive association of the several regulators that impacts the binding and property of RNA polymerase II, in riposte to numerous environs stress (Lioyd et al., 2001; Zhu, 1996). This could be an excellent platform for restructuring regulatory networks of gene, that assist to amend biological research and future expressional in-vitro analysis. Hence, plant productivity and development will pivot on well regulated $\mathrm{BADH}$ isoenzymes expression; though insilico analysis is a harbinger that assists in substantiating future expressional and functional invitro analysis.

\section{Acknowledgement}

Authors are grateful to School of Life Sciences, Jaipur National University, Jaipur for providing necessary infrastructure and support for this work.

\section{References}

1. Allakhverdiev, S.I., Kreslavski, V.D., Klimov, V.V., Los, D.A., Carpentier, R. and Mohanty, P. "Heat stress: an overview of molecular responses in photosynthesis." Photosynthesis Research 98 (2008): 541-550.

2. Allen, R.D., Bernier, F., Lessard, P.A. and Beachy, R.N. "Nuclear factors interact with a soybean betaconglycinin enhancer." Plant Cell 1 (1989): 623-631.

3. Bartels, D. and Sunkar, R. "Drought and salt tolerance in plants." Critical Reviews in Plant Sciences 24 (2005): 23-58.

4. Baumann, K., De, P.A., Costantino, P. and Gualberti, G. "The DNA binding site of the Dof protein NtBBF1 is essential for tissue-specific and auxin-regulated expression of the rolB oncogene in plants." Plant Cell 11 (1999): 323-333.

5. Cartharius, K., Frech, K., Grote, K., Klocke, B., Haltmeier, M., Klingenhoff, A., Frisch, M., Bayerlein, M. and Werner, T. "MatInspector and beyond: promoter analysis based on transcription factor binding sites." Bioinformatics 21 (2005): 29332942.

6. Chaboute, M.E., Clement, B. and Phillips, G. "S phase and meristem- specific expression of tobacco RNR1 b gene is mediated by an E2F element located in the 5' leader sequence." Journal of Biological Chemistry 277 (2002): 17845-17851.
7. Chang, W.C., Lee, T.Y., Huang, H.D., Huang, H.Y. and Pan, R.L. "PlantPAN: Plant promoter analysis navigator, for identifying combinatorial cisregulatory elements with distance constraint in plant gene groups.” BMC Genomics 9 (2008): 561-574.

8. Chattopadhyay, S., Puente, P., Deng, X.W. and Wei, $\mathrm{N}$. "Combinatorial interaction of light-responsive elements plays a critical role in determining the response characteristics of light-regulated promoters in Arabidopsis." Plant Journal 15 (1998): 69-77.

9. Chen, P.W., Chiang, C.M., Tseng, T.H. and Yu, S.M. "Interaction between rice MYBGA and the gibberellins response element controls tissue-specific sugar sensitivity of alpha-amylase genes" Plant Cell 18 (2006): 2326-2340.

10. Cherian, S. and Reddy, M.P. "Evaluation of $\mathrm{NaCl}$ Tolerance in the Callus Cultures of Suaeda nudiflora Moq.” Biologia Plantarum 46 (2003): 193-198.

11. Daraselia, N.D., Tarchevskaya, S. and Narita, J.O. "The promoter for tomato 3-hydroxy-3methylglutaryl coenzyme A reductase gene 2 has unusual regulatory elements that direct high level expression.” Plant Physiology 112 (1996): 727-733.

12. Dean, C. and Schmidt, R. "Plant genomes: a current molecular description." Annual Review of Plant Physiology 46 (1995): 395-418.

13. Degenhardt, J. and Tobin, E.M. "A DNA binding activity for one of two closely defined phytochrome regulatory elements in an Lhcb promoter is more abundant in etiolated than in green plants." Plant Cell 8 (1996): 31-41.

14. Doelling, J.H. and Pikaard, C.S. "The minimal ribosomal RNA gene promoter of Arabidopsis thaliana includes a critical element at the transcription initiation site." The Plant Journal 8(1995): 683-92.

15. Dubouzet, J.G., Sakuma, Y., Ito, Y., Kasuga, M., Dubouzet, E.G., Miura, S., Seki, M., Shinozaki, K. and Yamaguchi-Shinozaki, K. "OsDREB genes in rice, Oryza sativa L, encode transcription activators that function in drought-, high-salt- and coldresponsive gene expression." The Plant Journal 33 (2003): 751-763.

16. Ellerstrom, M., Stalberg, K., Ezcurra, I. and Rask, L. "Functional dissection of a napin gene promoter: identification of promoter elements required for embryo and endosperm-specific transcription." Plant Molecular Biology 32(1996): 1019-1027.

17. Fehlberg, V., Vieweg, M.F., Dohmann, E.M.N., Hohnjec, N., Puhler, A., Perlick, A.M. and Kuster, $H$. "The promoter of the leghaemoglobin gene VfLb29: functional analysis and identification of modules necessary for its activation in the infected cells of root nodules and in the arbuscule-containing cells of mycorrhizal roots." Journal of Experimental Botany 56 (2005): 799-806. 
18. Finkelstein, R.R. and Gibson, S.I. "ABA and sugar interactions regulating development: cross-talk or voices in a crowd?" Current Opinion of Plant Biology 5 (2002): 26-32.

19. Folorunsho, T.E., Ibraheem, O. and Nyadzayo, R.M. "Comparative bioinformatics study of 5 ' regulatory and coding regions of sucrose synthesizing isozymes of selected monocot crops." Merit Research Journal of Biochemistry and Bioinformatics 2 (2014): 5-27.

20. Forde, B.G., Heyworth, A., Pywell, J. and Kreis, M. "Nucleotide sequence of a B1 hordein gene and the identification of possible upstream regulatory elements in endosperm storage protein genes from barley, wheat and maize." Nucleic Acids Research 13 (1985): 7327-7339.

21. Fusada, N., Masuda, T., Kuroda, H., Shimada, H., Ohta, H. and Takamiya, K. "Identification of a novel cis-element exhibiting cytokinin-dependent protein binding in vitro in the 5 '-region of NADPHprotochlorophyllide oxidoreductase gene in cucumber." Plant Molecular Biology 59(2005): 631-645.

22. Gao, X.P., Wang, X.Y., Lu, Y.F., Zhang, L.Y., Shen, Y.Y., Liang, Z. and Zhang D.P. "Jasmonic acid is involved in the water-stress-induced betaine accumulation in pear leaves." Plant and Cell Physiology 45(2004): 742-750.

23. Goldsbrough, A.P., Albrecht, H. and Stratford, R. "Salicylic acid-inducible binding of a tobacco nuclear protein to a 10 bp sequence which is highly conserved amongst stress-inducible genes." The Plant Journal 3 (1993): 563-571.

24. Gowik, U., Burscheidt, J., Akyildiz, M., Schlue, U., Koczor, M., Streubel, M. and Westhoff, P. "Cisregulatory elements for mesophyll-specific gene expression in the $\mathrm{C} 4$ plant Flaveria trinervia, the promoter of the C4 phosphoenolpyruvate carboxylase gene." Plant Cell 16 (2004): 1077-1090.

25. Grace, M.L., Chandrasekharan, M.B., Hall, T.C. and Crowe, A.J. "Sequence and spacing of TATA box elements are critical for accurate initiation from the beta-phaseolin promoter." The Journal of Biological Chemistry 279 (2004): 8102-8110.

26. Gubler, F., Kalla, R., Roberts, J.K. and Jacobsen, J.V. "Gibberellin-regulated expression of a myb gene in barley aleurone cells: evidence for Myb transactivation of a high-pl alpha-amylase gene promoter." Plant Cell 7 (1995): 1879-1891.

27. Hamilton, D.A., Schwarz, Y.H. and Mascarenhas, J.P. "A monocot pollen-specific promoter contains separable pollen-specific and quantitative elements." Plant Molecular Biology 38 (1998): 663-669.

28. Hopkins, W.G. "Plant and inorganic nutrients, In: Introduction to Plant Physiology." 2nd ed. John Wiley and Sons Inc., USA, 1999.

29. Huang, N., Sutliff, T.D., Litts, J.C. and Rodriguez, R.L. "Classification and characterization of the rice alpha-amylase multigene family." Plant Molecular Biology 14 (1990): 655-668.

30. Hwang, Y.S., Karrer, E.E., Thomas, B.R., Chen, L. and Rodriguez, R.L. "Three cis-elements required for rice alpha-amylase Amy3D expression during sugar starvation." Plant Molecular Biology 36 (1998): 331-341.

31. Ibraheema, O., Bothab, C.E.J. and Bradleya, G. "In silico analysis of cis-acting regulatory elements in 5' regulatory regions of sucrose transporter gene families in rice (Oryza sativa Japonica) and Arabidopsis thaliana." Computational Biology and Chemistry 34 (2010): 268-283.

32. Julian-Sanchez, A., Riveros-Rosas, H., MartinezCastilla, L.P., Velasco-Garcia, R. and Munoz-Clares, R.A. "Phylogenetic and Structural Relationships of the Betaine Aldehyde Dehydrogenases." Ensymology and Molecular Biology of Carbonyl Metabolism Ed. Purdue University Press, 13 (2007): 64-76.

33. Kagaya, Y., Ohmiya, K. and Hattori, T. "RAV1, a novel DNA-binding protein, binds to bipartite recognition sequence through two distinct DNAbinding domains uniquely found in higher plants." Nucleic Acids Research 27 (1999): 470-478.

34. Khodary, S.E.A. "Effect of salicylic acid on the growth, photosynthesis and carbohydrate metabolism in salt-stressed maize plants." International Journal of Agriculture and Biology 6 (2004): $5-8$.

35. Kim, S.Y., Chung, H.J. and Thomas, T.L. "Isolation of a novel class of bZIP transcription factors that interact with ABA-responsive and embryospecification elements in the Dc3 promoter using a modified yeast one-hybrid system." Plant Journal 11 (1997): 1237-1251.

36. Kumar, G.M., Mamidala, P. and Podile, A.R. "Regulation of Polygalacturonase-inhibitory proteins in plants is highly dependent on stress and light responsive elements.” Plant Omics 2 (2009): 238-249.

37. Lam, E. and Chua, N.H. "ASF-2: a factor that binds to the cauliflower mosaicvirus $35 \mathrm{~s}$ promoter and a conserved GATA motif in Cab promoters." Plant Cell 1 (1989): 1147-1156.

38. Larkindale, J. and Vierling, E. "Core genome responses involved in acclimation to high temperature." Plant Physiology 146 (2008): 748-761.

39. Lee, T.I. et al., "Transcriptional regulatory networks in Saccharomyces cerevisiae." Science 298 (2002): 799-804.

40. Lescot, M., Dhais, P., Thijs, G., Marchal, K., Moreau, Y., Van de Peer, Y., Rouz, P. and Rombauts, S. "Plant CARE, a database of plant cisacting regulatory elements and a portal to tools for in silico analysis of promoter sequences." Nucleic Acids Research 30 (2002): 325-327. 
41. Li, G., Wu, H., Sun, Y. and Zhang, S. "Betaine Aldehyde Dehydrogenase (BADH) Expression and Betaine Production in Sugarbeet Cultivars with Different Tolerances to Drought Stress." Sugar Tech 18 (2015): 420-423.

42. Lindolf, A., Brautigam, M., Chawade, A., Olsson, O. and Olsson, B. "In silico analysis of promoter regions from cold-induced genes in rice (Oryza sativa L.) and Arabidopsis thaliana reveals the importance of combinatorial control." Bioinformatics 25 (2009): 1345-1348.

43. Liu, Y.H. and Jia, S.R. "Vascular-specific promoters and cis-regulatory elements." Chinese Journal of Biotechnology 19 (2003): 131-135.

44. Lohmann, J.U., Hong, R.L., Hobe, M., Busch, M.A., Parcy, F., Simon, R. and Weigel, R. "A Molecular Link between Stem Cell Regulation and Floral Patterning in Arabidopsis." Cell 105 (2003): 793-803.

45. Lopez-Ochoa, L., Acevedo-Hernandez, G., Martinez-Hernandez, A., Arguello-Astorga, G. and Herrera-Estrella, L. "Structural relationships between diverse cis-acting elements are critical for the functional properties of a $\mathrm{rbcS}$ minimal light regulatory unit." Journal of Experimental Botany 58 (2007): 4397-4406.

46. Lynch, M. and Force, A. "The probability of duplicate gene preservation by sub functionalization." Genetics 154 (2000): 459-473.

47. Maeda, K., Kimura, S., Demura, T., Takeda, J. and Ozeki, Y. "DcMYB1 acts as a transcriptional activator of the carrot phenylalanine ammonia-lyase gene (DcPAL1) in response to elicitor treatment, UV-B irradiation and the dilution effect." Plant Molecular Biology 59 (2005): 739-752.

48. Matarasso, N., Schuster, S. and Avni, A. "A novel plant cysteine protease has a dual function as a regulator of 1-aminocyclopropane-1-carboxylic acid synthase gene expression." Plant Cell 17 (2005): 1205-1216.

49. McWilliam, H., Li, W., Uludag, M., Squizzato, S., Park, Y.M., Buso, N., Cowley, A.P. and Lopez, R. "Analysis Tool Web services from the EMBL-EBI." Nucleic Acids Research 41 (2013): 597-600.

50. Mohanty, B., Krishnan, S.P.T., Swarup, S. and Bajic, V.B. "Detection and preliminary analysis of motifs in promoters of anaerobically induced genes of different plant species." Annals of Botany 96 (2005): 669-681.

51. Munoz-Clares, R.A., Riveros-Rosas, H., GarzaRamos, G., Gonzalez-Segura, L., Mujica-Jimenez, C. and Julian-Sanchez, A. "Exploring the evolutionary route of the acquisition of betaine aldehyde dehydrogenase activity by plant ALDH10 enzymes: implications for the synthesis of the osmoprotectant glycine betaine." BMC Plant Biology 14 (2014): 149.

52. Natr, L. and Lawlor, D.W. "Photosynthetic plant productivity." In: Pessarakli, M.(Ed.),
Photosynthesis Handbook, 2nd ed. C.R.C. Press, New York, USA, 2005.

53. Park, H.C, Kim, M.L., Kang, Y.H., Jeon, J.M., Yoo, J.H., Kim, M.C., Park, C.Y., Jeong, J.C., Moon, B.C. et al., "Pathogen- and $\mathrm{NaCl}$-induced expression of the SCaM-4 promoter is mediated in part by a GT-1 box that interacts with a GT-1-like transcription factor.” Plant Physiology 135 (2004): 2150-2161.

54. Pauli, S., Rothnie, H.M., Chen, G., He, X. and Hohn, T. "The cauliflower mosaic virus 35S promoter extends into the transcribed region." Journal of Virology 78 (2004): 12120-12128.

55. Piechulla, B., Merforth, N. and Rudolph, B. "Identification of tomato Lhc promoter regions necessary for circadian expression." Plant Molecular Biology 38 (1998): 655-662.

56. Plesch, G., Ehrhardt, T. and Mueller-Roeber, B "Involvement of TAAAG elements suggests a role for Dof transcription factors in guard cell-specific gene expression." The Plant Journal 28 (2001): 455464.

57. Qui, P. “Computational approaches for deciphering the transcriptional regulatory network by promoter analysis." Biosilico 1 (2003): 125-133.

58. Rhodes, D. and Hanson, A.D. "Quaternary ammonium and tertiary sulfonium compounds in higher plants." Annual Review of Plant Physiology and Plant Molecular Biology 44 (1993): 357-384.

59. Rogers, J.C., Lanahan, M.B. and Rogers, S.W. "The cis-acting gibberellin response complex in high-pl aamylase gene promoters." Plant Physiology 105 (1994): $151-158$.

60. Rushton, P.J. and Somssich, I.E. "Transcriptional control of plant genes responsive to pathogens." Current Opinion in Plant Biology 1 (1998): 311-315.

61. Satoh, R., Nakashima, K., Seki, M., Shinozaki, K. and Yamaguchi-Shinozaki, K. "A novel subgroup of bZIP proteins functions as transcriptional activators in hypoosmolarity-responsive expression of the ProDH gene in Arabidopsis." Plant and Cell Physiology 45 (2004): 309-317.

62. Shinozaki, K., Yamaguchi, K et al., "Regulatory network of gene expression in the drought and cold stress responses." Current Opinion in Plant Biology 6 (2003): 410-417.

63. Shinozaki, K. and Yamaguchi-Shinozaki, K. "Molecular responses to dehydration and low temperature: differences and cross-talk between two stress signaling pathways." Current Opinion in Plant Biology 3 (2000): 217-223.

64. Shirsat, A., Wilford, N., Croy, R. and Boulter, D. "Sequences responsible for the tissue specific promoter activity of a pea legumin gene in tobacco." Molecular and General Genetics 215 (1989): 326-331. 
65. Tatematsu, K., Ward, S., Leyser, O., Kamiya, Y. and Nambara, E. "Identification of cis-elements that regulate gene expression during initiation of axillary bud outgrowth in Arabidopsis." Plant Physiology 138 (2005): 757-766.

66. Terzaghi, W.B. and Cashmore, A.R. "Light-regulated transcription." Annual Review of Plant Physiology and Plant Molecular Biology 46 (1995): 445-474.

67. Tian, F., Wang, W., Liang, C., Wang, X., Wang, G. and Wang, W. "Over accumulation of glycine betaine makes the function of the thylakoid membrane better in wheat under salt stress." The Crop Journal 5 (2017): 73-82.

68. Trehin, C., Ahn, I.O., Perennes, C., Couteau, F., Lalanne, E. and Bergounioux, C. "Cloning of upstream sequences responsible for cell cycle regulation of the Nicotiana sylvestris $\mathrm{CycB} 1 ; 1$ gene." Plant Molecular Biology 35 (1997): 667-721.

69. Vilo, J., Brazma, A., Jonassen, I., Robinson, A. and Ukkonen, E. "Mining for putative regulatory elements in the yeast genome using gene expression data, In: Proc 8th Int Conf on Intelligent Systems for Molecular Biology." AAAI Press, Menlo Park,California, (2000): 384-394.

70. Wang, Z., Dalkilic, M. and Kim, S. "Guiding motif discovery by iterative pattern refinement." In: $A C M$
Symposium on Applied Computing Nicosia, Cyprus, (2004): 162-166

71. Washida, H., Wu, C.Y., Suzuki, A., Yamanouchi, U., Akihama, T. et al., "Identification of cis-regulatory elements required for endosperm expression of the rice storage protein glutelin gene GluB-1." Plant Molecular Biology 40 (1999): 1-12.

72. Xiong, L. and Zhu, J.K. "Molecular and genetic aspects of plant responses to osmotic stress." Plant Cell Environment 25 (2002): 131-139.

73. Yang, T. and Poovaiah, B.W. "A calmodulinbinding/CGCG box DNA-binding protein family involved in multiple signaling pathways in plants." The Journal of Biological Chemistry 277 (2002): 4504945058.

74. Zhu, Q. "RNA polymerase II-dependent plant in vitro transcription systems." The Plant Journal 10 (1996): 185-188.

\section{Cite this article as:}

Hemani Sharma, Sumit Govil and Divya Shrivastava. In-silico identification of cis- acting regulatory elements in 5' regulatory region of Betaine aldehyde dehydrogenase isoenzymes of selected monocot and dicot. Annals of Plant Sciences 7.2 (2018) pp. 2026-2036.

do http://dx.doi.org/10.21746/aps.2018.7.2.8

Source of support: School of Life Sciences, Jaipur National University, Jaipur Conflict of interest: Nil 